\title{
Patient Preferences for Attributes of Type 2 Diabetes Mellitus Medications in Germany and Spain: An Online Discrete-Choice Experiment Survey
}

\author{
Carol Mansfield · Mirko V. Sikirica · Amy Pugh · Christine M. Poulos • \\ Victoria Unmuessig · Raul Morano · Alan A. Martin
}

Received: August 17, 2017 / Published online: November 3, 2017

(C) The Author(s) 2017. This article is an open access publication

\begin{abstract}
Introduction: Understanding patient preferences for attributes of type 2 diabetes mellitus (T2DM) medications may help explain how the attributes differentially affect patient perceptions and behaviors. In this survey, we

Enhanced content To view enhanced content for this article go to http://www.medengine.com/Redeem/ 0BCCF0603FFD36A6.
\end{abstract}

Electronic supplementary material The online version of this article (doi:https://10.1007/s13300-0170326-8) contains supplementary material, which is available to authorized users.

C. Mansfield · A. Pugh · C. M. Poulos

RTI Health Solutions, Research Triangle Park, NC, USA

M. V. Sikirica $(\square)$

GlaxoSmithKline, Collegeville, PA, USA

e-mail: Mirko.x.sikirica@gsk.com

Present Address:

A. Pugh

San Francisco School of Medicine, University of

California, San Francisco, USA

V. Unmuessig

GlaxoSmithKline, Munich, Germany

R. Morano

GlaxoSmithKline, Madrid, Spain

A. A. Martin

GlaxoSmithKline, Brentford, UK quantified the relative preferences among patients in Germany and Spain in separate analyses.

Methods: A stated-preference, discrete-choice experiment (DCE) survey was designed to elicit preferences for T2DM treatment attributes among patients with self-reported T2DM and who reported being prescribed T2DM medication for $>2$ years. Patients recruited from an online national consumer panel completed an online survey. The survey presented choices between eight pairs of hypothetical T2DM treatments defined by seven attributes: chance of reaching target hemoglobin A1c (HbA1c) level; reduced risk of serious heart attack or stroke; frequency of hypoglycemia; risk of gastrointestinal (GI) problems; weight change; mode of administration (oral or injectable); dosing frequency. Data were analyzed using random-parameters logit. Minimum acceptable benefit (MAB) was defined as the minimum increase in the probability of reaching target HbA1c for which respondents would accept less desirable levels of other attributes.

Results: In Germany and Spain, 474 and 401 respondents completed the survey, respectively. DCE analysis showed that risk of GI problems was most important to German respondents. MAB analysis found that respondents would require a 56 percentage point increase in the probability of reaching their HbA1c target to offset a change from $0 \%$ to $30 \%$ risk of GI problems. For Spanish respondents, mode of 
administration was the most important attribute. These respondents would require a 59 percentage point increase in the probability of reaching their HbA1c target to offset moving from oral to injectable medications.

Conclusions: Respondents in Germany and Spain were willing to trade efficacy for improvements in side effects and mode of administration. Given the variety of T2DM medications currently available, the results suggest that careful discussion about patient preferences could help improve patient satisfaction with T2DM treatment.

Keywords: Diabetes; Discrete-choice experiment; Germany; Glucose control; Patient preferences; Spain; Type 2 diabetes mellitus

\section{INTRODUCTION}

Type 2 diabetes mellitus (T2DM) is a common chronic disease and a growing worldwide epidemic [1]. According to a recent measure (in 2013), the prevalence of diabetes in Europe was $8.5 \%$ [2]. In Germany in 2010, the estimated number of individuals aged 55-74 years with T2DM was 2.4 million and is expected to rise to 3.9 million by 2030 [3]. In Spain, 30\% of participants in the Di@bet.es cross-sectional study of a representative random sample of the Spanish population had some glucose disturbance, and the prevalence of diabetes mellitus was $13.8 \%$ [4]. Complications from diabetes lead to increased disability and high healthcare costs [2], highlighting the need for better preventive measures and treatment options.

A range of treatments are available to control patient blood glucose levels. This variety of treatment options naturally provides a diversity of clinical efficacy, modes of administration, and adverse event profiles.

Patient preferences are one of the most important factors to consider when making a drug choice. Because the variety of treatment options available for T2DM has increased, the importance of understanding patient preferences for available agents has similarly increased. With the introduction of medications with new mechanisms of action and side effect profiles, it is vital to determine how patient perceptions of specific treatment attributes vary in order to understand how such attributes might affect patient treatment choices [5-10].

Researchers have started using stated-preference surveys, such as discrete-choice experiments (DCEs), to evaluate the relative preference for features of medical interventions [11]. The basis for DCEs is the principle that products comprise a set of attributes and that the value of a product to an individual is a function of these attributes [12]. This approach provides information on people's willingness to accept tradeoffs between features of multi-attribute products, recognizing that individuals place different levels of importance on different product attributes [13]. An added benefit of this approach is the ability to obtain information about new treatments or treatment attributes before the drugs enter the marketplace. The primary objective of the study reported here was to quantify preferences for attributes of T2DM treatments among patients with T2DM in Germany and Spain using a DCE survey.

\section{METHODS}

\section{Survey Development}

An online survey was developed that included questions on demographics (age, sex, marital status, level of education, employment status), disease experience [time since diagnosis, current and target hemoglobin A1c (HbA1c) levels, and experience with T2DM treatments], and DCE questions about treatment choice.

The DCE questions posed a choice between two hypothetical treatments for T2DM, with each treatment being defined by a set of seven attributes at varying levels: (1) the chance of achieving the respondent's HbA1c target; (2) reduced risk of serious heart attack or stroke; (3) frequency of hypoglycemic events; (4) risk of gastrointestinal (GI) problems; (5) changes in body weight; (6) mode of administration; (7) frequency of dosing (Table 1). In the final online survey, each of the seven attributes was described separately, and the descriptions were followed by questions about the attribute to ensure respondents' understanding. The three 
Table 1 Attribute levels for discrete-choice experiment

\begin{tabular}{|c|c|}
\hline Attribute & Levels \\
\hline $\begin{array}{c}\text { Chance that medication } \\
\text { works well to control } \\
\text { blood sugar (HbAlc) }\end{array}$ & $\begin{array}{l}100 \text { of } 1000 \text { people }(10 \%) \\
\text { reach target HbAlc } \\
300 \text { of } 1000 \text { people }(30 \%) \\
\text { reach target HbAlc } \\
500 \text { of } 1000 \text { people }(50 \%) \\
\text { reach target HbAlc }\end{array}$ \\
\hline $\begin{array}{l}\text { Reduction in risk of serious } \\
\text { heart attack or stroke }\end{array}$ & $\begin{array}{l}35 \text { of } 1000 \text { patients } \\
\text { experience serious heart } \\
\text { attack or stroke ( } 5 \% \\
\text { reduction in risk) } \\
37 \text { of } 1000 \text { patients } \\
\text { experience serious heart } \\
\text { attack or stroke (no risk } \\
\text { reduction) }\end{array}$ \\
\hline Hypoglycemic events (hypos) & $\begin{array}{l}\text { No hypos } \\
\text { 1-2 hypos per year } \\
\text { 1-2 hypos per month } \\
\quad(12-24 \text { per year) } \\
>2 \text { hypos per month } \\
\quad>24 \text { per year) }\end{array}$ \\
\hline Risk of GI problems & $\begin{array}{l}0 \% \text { (no risk of GI } \\
\text { problems) } \\
100 \text { of } 1000 \text { people }(10 \%) \\
\text { have GI problems } \\
200 \text { of } 1000 \text { people }(20 \%) \\
\text { have GI problems } \\
300 \text { of } 1000 \text { people }(30 \%) \\
\text { have GI problems }\end{array}$ \\
\hline Weight change & $\begin{array}{l}\text { 2-kg weight loss } \\
\text { No weight change } \\
\text { 2-kg weight gain }\end{array}$ \\
\hline Mode of administration & $\begin{array}{l}\text { Pill } \\
\text { Injectable }\end{array}$ \\
\hline
\end{tabular}

Table 1 continued

\begin{tabular}{ll}
\hline Attribute & Levels \\
\hline Dosing frequency & Once a week \\
& Once a day \\
& Twice a day \\
& More than twice a day \\
\hline
\end{tabular}

HbA1c Glycated hemoglobin A1, GI gastrointestinal

probabilistic attributes, namely, the chance of achieving an HbA1c target, reduced risk of serious heart attack or stroke, and risk of GI problems, were explained graphically using risk grids in which colored dots identified the number of treated patients for whom the event occurred (Fig. 1). Research suggests that pictograms such as risk grids are an effective method of communicating risk [14]. Respondents were asked to review a sample risk grid, following which they were asked a comprehension question about the risk grid. Respondents who answered incorrectly were presented with the correct answer and an explanation before proceeding with the survey, while respondents who answered correctly were presented with the correct answer to reinforce their understanding. The survey was pretested to evaluate the survey instrument in 14 face-to-face interviews conducted in Berlin, Germany, and 15 face-to-face interviews conducted in Barcelona, Spain.

An experimental design was used to create the pairs of hypothetical treatments included in the DCE questions, following good practice guidelines [15]. The design was generated using SAS 9.3 analytics software (SAS Institute Inc., Cary, NC). The final design included 48 DCE questions divided into six blocks of eight questions each. Each patient was randomly assigned one block of DCE questions, and each DCE question asked the patient to indicate which treatment they would choose if the two treatments in the question were the only treatments available [14, 15]. 


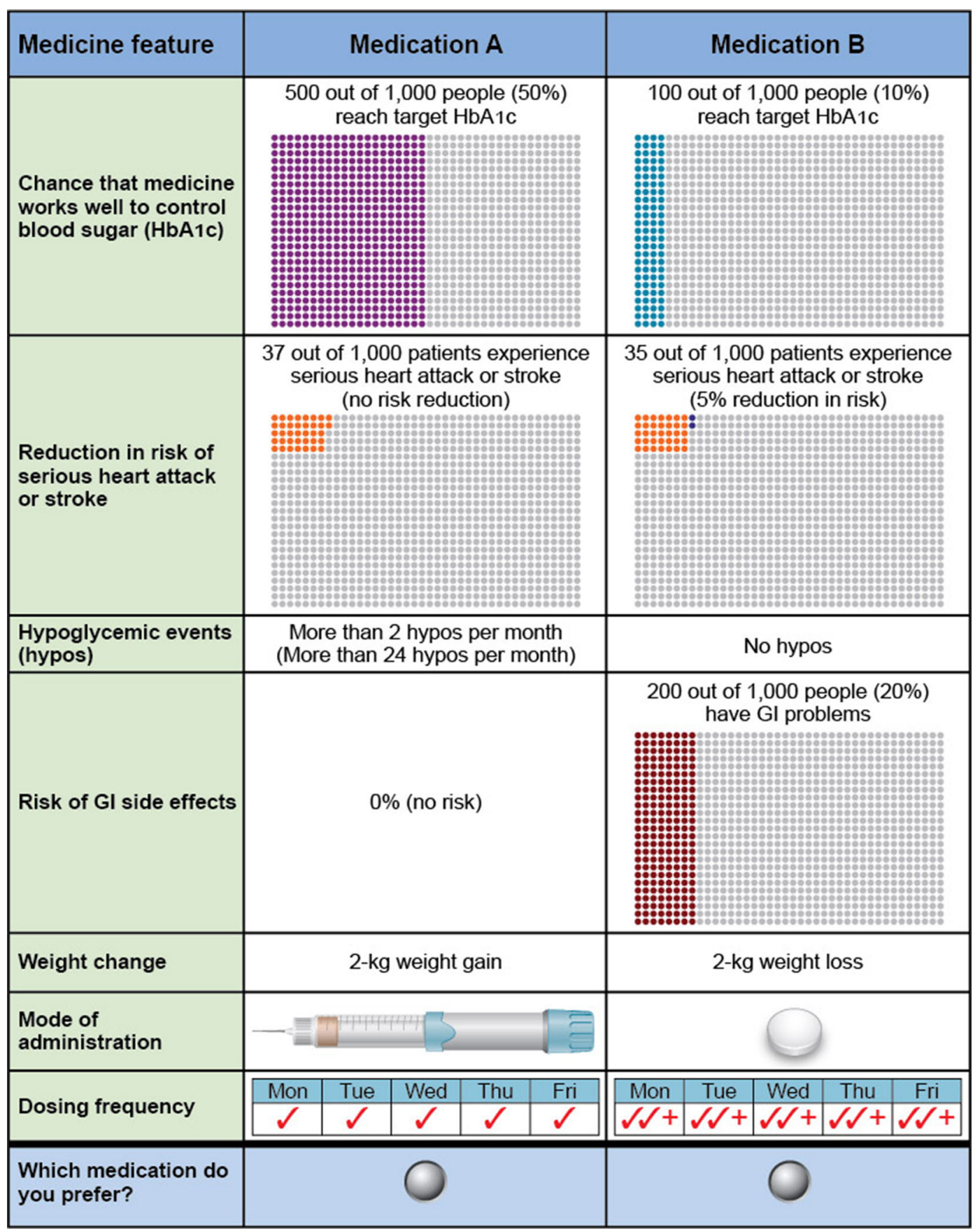

Fig. 1 Example of discrete-choice experiment question. The images depict the number of patients out of 1000 who reached each goal as colored dots and those who did not as gray dots. The two blue dots in the reduction in risk of

\section{Survey Populations}

Patients were recruited from local communities for inclusion in survey pretesting and from an serious heart attack or stroke depict the $5 \%$ reduction in risk with Medication B versus Medication A. HbAlc Glycated hemoglobin A1, GI gastrointestinal

online national consumer panel for inclusion in the online survey. Patients were required to be residents of Germany or Spain, be aged $\geq 18$ years, be able to read and understand 
German or Spanish, and provide informed consent. Eligible patients were also required to have a self-reported physician diagnosis of T2DM, have first started medication at least 2 years prior to taking the survey, and be receiving ongoing treatment with at least one T2DM prescription medication at the time of the survey. For the online survey, $\geq 200$ respondents of both sexes in each country were sought. The study was approved by an institutional review board of RTI International (Research Triangle Park, NC, USA). All procedures followed were in accordance with the ethical standards of the responsible committee on human experimentation (institutional and national) and with the Helsinki Declaration of 1964, as revised in 2013. All patients provided informed consent prior to their inclusion in the study.

\section{Statistical Analysis}

The primary endpoint was the average preference weight for each attribute level of T2DM medications included in the survey (Table 1). The data from Germany and Spain were analyzed separately. The DCE choice data were estimated using random-parameters logit, a limited dependent variable regression model that avoids potential estimation bias from unobserved preference heterogeneity among respondents [16, 17]. All treatment attribute levels were included in the model as effectscoded categorical variables, except for the chance of reaching target $\mathrm{HbA1c}$ level, which was modeled as a linear continuous variable [12]. The coefficients on the independent variables from the random-parameters logit regression can be interpreted as relative preference weights, indicating the relative strength of preference for each attribute level. Larger positive coefficients indicated that respondents preferred that attribute level to levels that had smaller or negative coefficients. A Wald test was used to test for differences between adjacent attribute levels, and the NLOGIT 5 software package (Econometric Software, Inc., Plainview, NY) was used for the multivariate data analysis.
Separate random-parameters logit models were estimated and tested for differences in preferences between the following subgroups separately in each country: male versus female; age $<65$ years versus age $\geq 65$ years; self-reported T2DM diagnosis of $<7$ years prior to survey versus $\geq 7$ years prior to survey; use of injectable versus oral therapy at the time of the survey. The results of these exploratory analyses of preference heterogeneity are shown in the Electronic Supplementary Materials (ESM).

The estimated preference weights from the random-parameters logit model were used to calculate the relative preferences for medication profiles defined by the attributes and levels shown in Table 1 . These medication profiles were created to approximate T2DM medications that would be the most likely comparators if a new injectable medication entered the market. For Germany, these were: a sulfonylurea (e.g., glipizide), a prandial insulin (e.g., insulin lispro), a once-daily glucagon-like peptide-1 receptor agonist (GLP-1 RA; e.g., liraglutide), and a onceweekly GLP-1 RA (e.g., albiglutide) (Table 2); for Spain, these were: a once-daily GLP-1 RA (e.g., liraglutide), a basal insulin (e.g., insulin glargine), a prandial insulin (e.g., insulin lispro), and a once-weekly GLP-1 RA (e.g., albiglutide) (Table 2). To calculate the proportion of the sample that may choose each of the four medication profiles, we calculated a net clinical benefit score for each medication as the weighted sum of each medication profile's attribute levels, where the weights represent the relative strength of preference for the corresponding attribute level in the medication profile.

A minimum acceptable benefit (MAB) for changes in attribute levels was also calculated. The MAB is interpreted as the minimum change in efficacy that respondents would require (on average) to accept changes in other attributes. In this case, it is the minimum increase in the probability that the medication will achieve the target HbA1c level required to compensate respondents for change to a less desirable level in another attribute. MAB was calculated as the difference between the preference weights for two levels of an attribute divided by the preference weight for increasing the probability of 


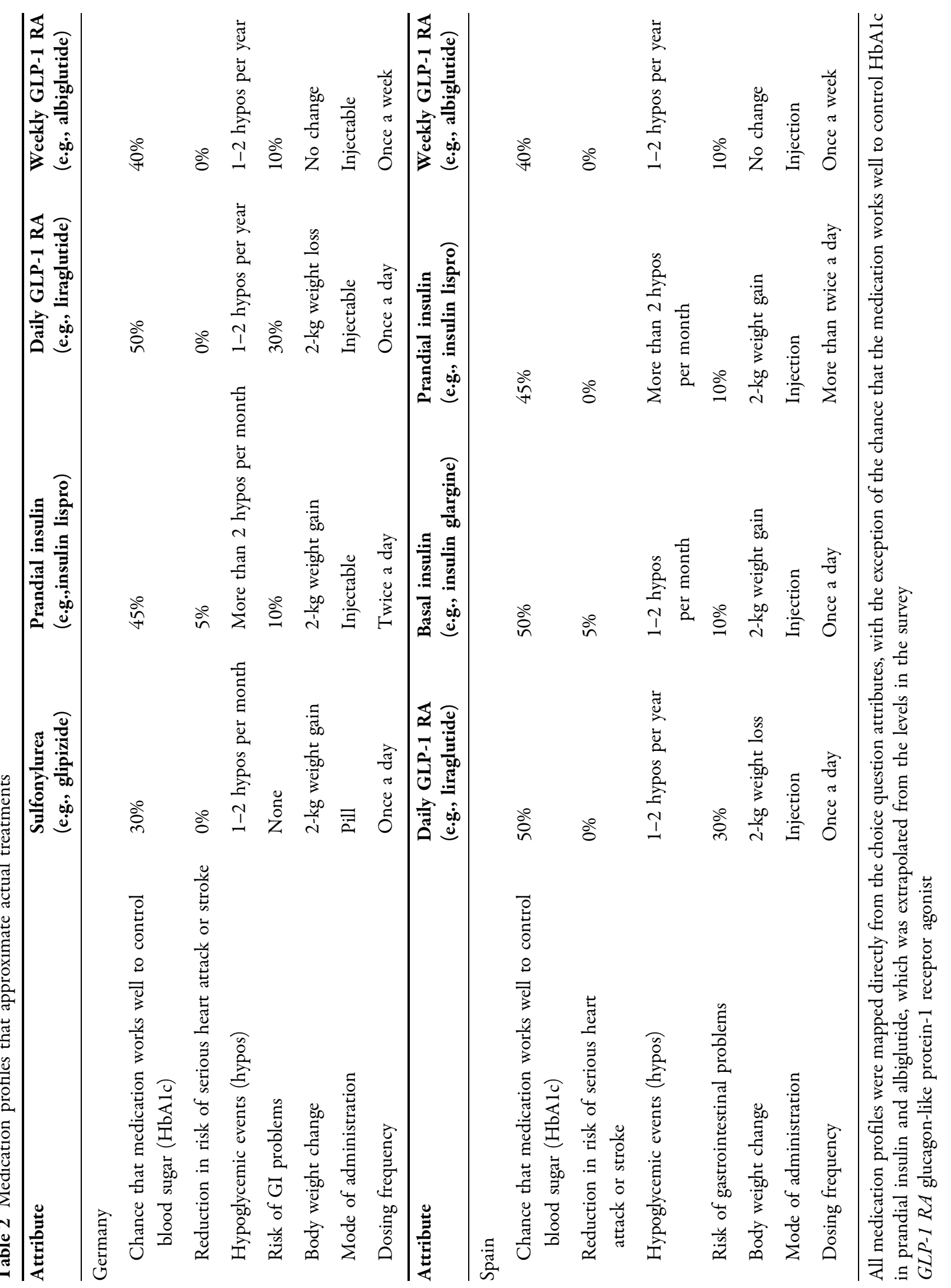


achieving the target HbA1c level by 1 percentage point.

\section{RESULTS}

\section{Study Populations}

In Germany, 1198 individuals responded to the invitation to take part in the survey. Of those who responded, $531(44.3 \%)$ were eligible to participate, of whom 474 (89.3\% of those eligible) provided consent and completed the survey. In Spain, 1584 individuals responded to the invitation to take the survey. Of those who responded, $446(28.2 \%)$ were eligible to participate, of whom 401 (89.9\% of those eligible) provided consent and completed the survey. The German and Spanish respondents were generally similar, although they differed in that the Spanish group included proportionately more men, had an overall shorter self-reported duration of diabetes, and had more respondents with HbA1c level > 8.0\% (Table 3).

\section{Results of DCE Model}

The results from the DCE analyses are provided in Fig. 2a, b. The estimated preference weights for all attributes were generally consistent with the expected ordering of levels within each attribute; that is, better outcomes were preferred to worse outcomes. Two exceptions that did not follow the expected ordering were dosing frequency among German respondents (Fig. 2a) and risk of GI problems among Spanish respondents (Fig. 2b); however, there was no statistically significant difference between the attribute levels in either case (respondents were indifferent in their choices between the levels). For Germans (Fig. 2a), the most important change was from no risk of GI problems to a 30\% risk of GI problems, whereas reducing the risk of serious heart attack or stroke by $5 \%$ was the least important change. For Spaniards (Fig. 2b), the most important change was a switch from oral to injectable mode of administration, and the least important change was also a $5 \%$ reduction in the risk of serious heart attack or stroke.
Table 3 Demographics and background characteristics

\begin{tabular}{|c|c|c|}
\hline $\begin{array}{l}\text { Demographics and } \\
\text { background characteristics }\end{array}$ & $\begin{array}{l}\text { Germany } \\
(N=474)\end{array}$ & $\begin{array}{l}\text { Spain } \\
(N=401)\end{array}$ \\
\hline \multicolumn{3}{|l|}{ Sex } \\
\hline Male & $274(57.8)$ & $267(66.6)$ \\
\hline Female & $200(42.2)$ & $134(33.4)$ \\
\hline \multicolumn{3}{|l|}{ Age (years) } \\
\hline $\begin{array}{l}\text { Mean ( } \pm \text { standard } \\
\text { deviation })\end{array}$ & $61.1 \pm 9.4$ & $\begin{array}{c}50.8 \pm \\
13.5\end{array}$ \\
\hline \multicolumn{3}{|l|}{ Self-reported duration of diabetes } \\
\hline$\leq 3$ years ago & $71(15.0)$ & $103(25.7)$ \\
\hline $\begin{array}{l}>3 \text { years ago but }<7 \text { years } \\
\text { ago }\end{array}$ & $145(30.6)$ & $165(41.1)$ \\
\hline$\geq 7$ years ago & $257(54.2)$ & $131(32.7)$ \\
\hline Don't know & $1(0.2)$ & $2(0.5)$ \\
\hline \multicolumn{3}{|c|}{ Diabetes medications currently being used } \\
\hline Only oral & $278(58.6)$ & $226(56.4)$ \\
\hline Only injectable & $56(11.8)$ & $65(16.2)$ \\
\hline Both oral and injectable & $140(29.5)$ & $110(27.4)$ \\
\hline \multicolumn{3}{|c|}{$\begin{array}{l}\text { Self-reported HbAlc among respondents who had heard } \\
\text { of HbAlc before the survey (Germany, } n=369) \text { (Spain, } \\
n=257 \text { ) }\end{array}$} \\
\hline $\begin{array}{l}\text { Don't know or can't } \\
\text { remember }\end{array}$ & $23(6.2)$ & $37(14.4)$ \\
\hline$\leq 6.5 \%$ & $136(36.9)$ & $62(24.1)$ \\
\hline $6.6-7.0 \%$ & $84(22.8)$ & $45(17.5)$ \\
\hline $7.1-8.0 \%$ & $82(22.2)$ & $54(21.0)$ \\
\hline$>8.0 \%$ & $44(11.9)$ & $59(23.0)$ \\
\hline
\end{tabular}

Values in table are presented as a number with the percentage in parenthesis unless otherwise indicated

Most of the differences in preference weights between adjacent levels within a single attribute were statistically significant $(p \leq 0.05)$, indicating that respondents, on average, distinguished between the levels when making medication choices. Exceptions among German participants were for comparisons of dosing frequency (once a week versus once a day, once a week 

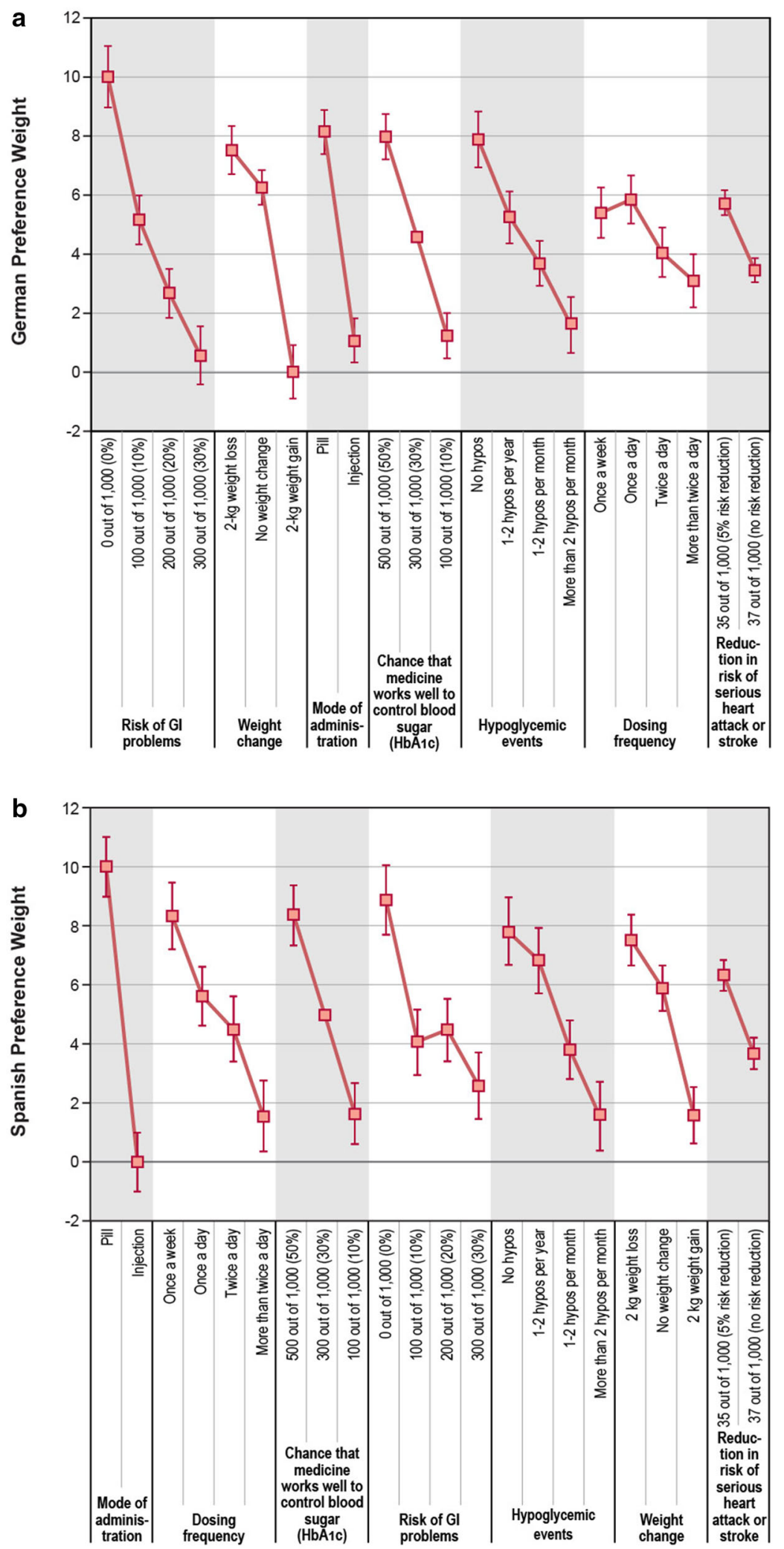
4Fig. 2 Overall preference weight results presented as the mean (symbol) and 95\% confidence interval (whiskers). a German preference weights, b Spanish preference weights

versus twice a day, and twice a day versus more than twice a day). Exceptions among Spanish participants were in dosing frequency (once a day versus twice a day), risk of GI problems (10 versus $20 \%$ and 10 versus $30 \%$ ), and in hypoglycemic events (no hypoglycemic events versus 1-2 hypoglycemic events per year).

\section{Subgroup Analysis of DCE Results}

Subgroup analysis revealed no statistically significant differences between subgroups based on sex or age in either the German or Spanish analysis (data not shown). For both nationalities, there were statistically significant differences in preferences between respondents using injectable treatments at the time of the survey versus those who were not. The detailed results of the subgroup analysis are presented in ESM Fig. S1.

\section{Minimum Acceptable Benefit}

The MAB levels required (in percentage point increases in the chance of reaching HbA1c target levels) to compensate respondents for worsening levels of other treatment attributes are presented in Table 4. Among German respondents, the highest MAB levels were seen for moving from a $0 \%$ risk of GI problems to a $30 \%$ risk of GI problems, which required a 56.0 percentage point increase in the chance of reaching target $\mathrm{HbA1c}$ to offset. Other substantial MAB levels included changes from 2-kg body-weight loss to 2-kg body-weight gain (44.4 percentage point increase), no risk of GI problems to $20 \%$ risk of GI problems (43.4 percentage point increase), oral to injectable mode of administration (42.0 percentage point increase), no hypoglycemic events to $>2$ hypoglycemic events per month (37.3 percentage point increase), and no body weight change to a $2-\mathrm{kg}$ body weight gain (37.1 percentage point increase).
Among Spanish respondents, the highest MAB levels were observed for avoiding injections, which required a 59.4 percentage point increase in the chance of reaching target HbA1c to offset, followed by changes in dosing frequency of once a week to more than twice a day (40.3 percentage point increase), risk of GI problems from $0 \%$ to $30 \%$ (37.4 percentage point increase), no hypoglycemic events to $>2$ hypoglycemic events per month (37.3 percentage point increase), and a $2-\mathrm{kg}$ loss in body weight to a $2-\mathrm{kg}$ gain in body weight (35.4 percentage point increase) (Table 4).

For several comparisons of dosing frequency among German respondents, the MAB 95\% confidence intervals included zero, suggesting that the respondents were not willing to trade-off efficacy in controlling HbA1c for changes in dosing frequency. Among Spanish respondents, 95\% confidence intervals crossing zero were observed for comparisons between frequencies of hypoglycemic events, GI problems, and dosing frequency (Table 4).

\section{Predicted Proportion of Sample Choosing Specific Medicines}

The results from the random-parameters logit model were used to calculate preference shares for hypothetical medicine profiles, which indicate the proportion of the population expected to select a particular hypothetical medicine if given a choice between stated alternatives. Among German respondents (Fig. 3a), the oral sulfonylurea (glipizide-like) profile was predicted to have the greatest preference share among patients (44.4\%). The second-ranked hypothetical medication was the injectable once-weekly GLP-1 RA (albiglutide-like) profile (27.1\%). Among German respondents using injectable treatments (Fig. 3b), a once-weekly GLP-1 RA (albiglutide-like) profile had the largest preference share (45.1\%).

Among Spanish respondents (Fig. 3c), the once-weekly GLP-1 RA (albiglutide-like) profile was most preferred $(39.7 \%)$, followed by the once-daily GLP-1 RA (liraglutide-like) profile 
Table 4 Minimum acceptable benefit for changes in attribute levels

\begin{tabular}{|c|c|c|c|}
\hline \multirow[t]{2}{*}{ Attribute } & \multirow[t]{2}{*}{ Change } & \multicolumn{2}{|c|}{$\begin{array}{l}\text { Mean minimum acceptable benefit: } \\
\text { percentage point increase in probability of } \\
\text { reaching target blood sugar }(\mathrm{HbAlc})^{\mathrm{a}}\end{array}$} \\
\hline & & Germany & Spain \\
\hline $\begin{array}{l}\text { Reduction in risk of serious } \\
\text { heart attack or stroke }\end{array}$ & $\begin{array}{l}5 \% \text { reduction in risk of serious heart } \\
\text { attack or stroke to no risk reduction }\end{array}$ & $13.5(8.6-18.2)$ & $15.8(9.6-21.6)$ \\
\hline \multirow{6}{*}{$\begin{array}{l}\text { Hypoglycemic events } \\
\text { (hypos) }\end{array}$} & No hypos to $1-2$ hypos per year & $15.6(6.6-24.5)$ & $5.9(-5.1$ to 17.0$)$ \\
\hline & No hypos to $1-2$ hypos per month & $24.9(16.8-32.8)$ & $23.8(13.9-33.5)$ \\
\hline & No hypos to $>2$ hypos per month & $37.3(27.8-47.4)$ & $37.3(25.6-48.9)$ \\
\hline & $\begin{array}{l}\text { 1-2 hypos per year to } 1-2 \text { hypos per } \\
\text { month }\end{array}$ & $9.2(1.2-16.6)$ & $17.9(7.3-27.5)$ \\
\hline & $\begin{array}{l}\text { 1-2 hypos per year to }>2 \text { hypos per } \\
\text { month }\end{array}$ & $21.7(12.4-29.9)$ & $31.4(20.0-41.6)$ \\
\hline & $\begin{array}{l}\text { 1-2 hypos per month to }>2 \text { hypos per } \\
\text { month }\end{array}$ & $12.5(4.4-21.1)$ & $13.5(3.2-24.7)$ \\
\hline \multirow[t]{6}{*}{ Risk of GI problems } & $0 \%$ to $10 \%$ of people have GI problems & $28.7(19.9-37.1)$ & $28.6(17.1-39.9)$ \\
\hline & $0 \%$ to $20 \%$ of people have GI problems & $43.4(34.8-52.5)$ & $26.2(15.7-36.5)$ \\
\hline & $0 \%$ to $30 \%$ of people have GI problems & $56.0(45.9-66.2)$ & $37.4(26.3-48.7)$ \\
\hline & $10 \%$ to $20 \%$ of people have GI problems & $14.7(6.8-22.7)$ & $-2.5(-12.7$ to 8.4$)$ \\
\hline & $10 \%$ to $30 \%$ of people have GI problems & $27.2(18.7-36.1)$ & $8.7(-2.1$ to 19.6$)$ \\
\hline & $20 \%$ to $30 \%$ of people have GI problems & $12.5(4.5-21.3)$ & $11.2(1.2-22.4)$ \\
\hline \multirow[t]{3}{*}{ Body weight change } & $\begin{array}{l}\text { 2-kg body weight loss to no change in } \\
\text { body weight }\end{array}$ & $7.4(0.7-12.1)$ & $9.7(1.2-16.0)$ \\
\hline & $\begin{array}{l}\text { No change in body weight to body weight } \\
\text { gain of } 2 \mathrm{~kg}\end{array}$ & $37.1(29.4-44.6)$ & $25.6(16.6-34.1)$ \\
\hline & $\begin{array}{l}\text { 2-kg loss in body weight to gain in body } \\
\text { weight of } 2 \mathrm{~kg}\end{array}$ & $44.4(35.1-54.3)$ & $35.4(26.0-45.2)$ \\
\hline Mode of administration & Oral or injection & $42.0(33.3-51.1)$ & $59.4(47.8-71.6)$ \\
\hline \multirow[t]{6}{*}{ Dosing frequency } & Once a week to once a day & $-2.6(-9.6$ to 4.7$)$ & $16.1(6.7-25.6)$ \\
\hline & Once a day to twice a day & $10.5(2.8-18.6)$ & $6.6(-3.0$ to 16.9$)$ \\
\hline & Once a week to twice a day & $8.0(-0.7$ to 16.5$)$ & $22.8(11.7-34.0)$ \\
\hline & Once a week to more than twice a day & $13.6(4.7$ to -22.6$)$ & $40.3(28.6-52.1)$ \\
\hline & Once a day to more than twice a day & $16.2(7.6-24.6)$ & $24.2(13.7-34.9)$ \\
\hline & Twice a day to more than twice a day & $5.6(-2.1$ to 13.2$)$ & $17.5(6.9-27.5)$ \\
\hline
\end{tabular}

a $95 \%$ Confidence interval is given in parenthesis 

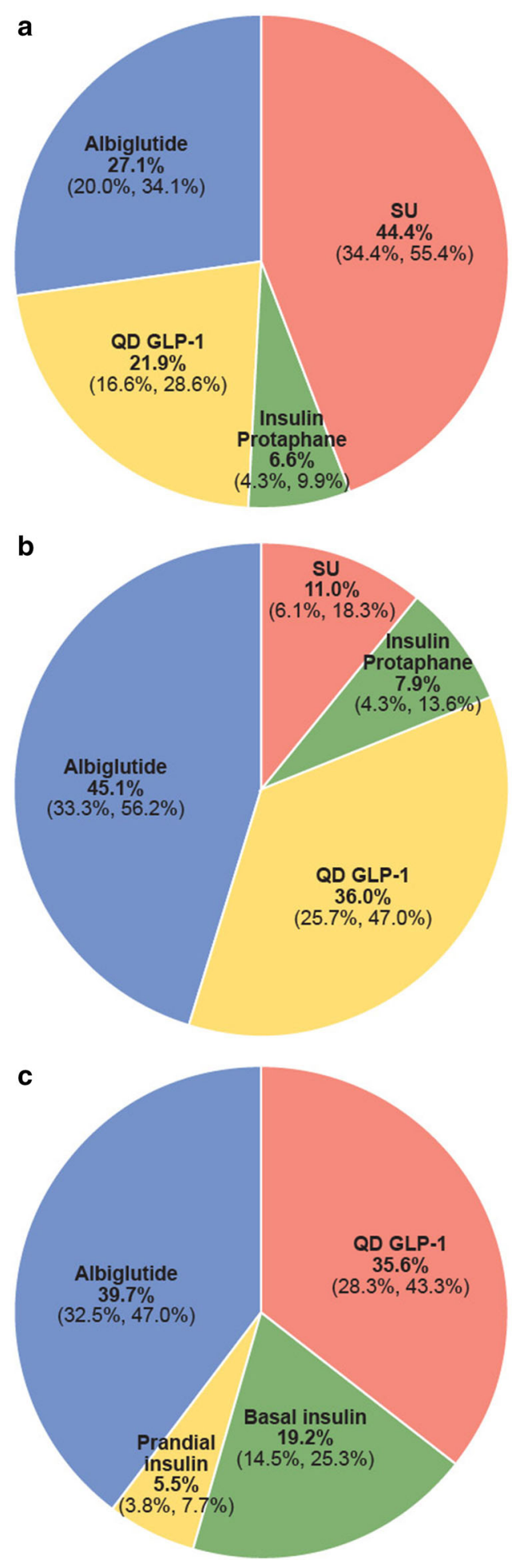

(35.6\%). The model predicted smaller preference shares for basal insulin (19.2\%) or prandial insulin (5.5\%).
4Fig. 3 Predicted preference shares for hypothetical treatments based on discrete-choice experiment results (mean with the $95 \%$ confidence interval in parenthesis). a German respondents, b German respondents using injectable treatments, c Spanish respondents. GLP-1 Glucagon-like protein-1 receptor agonist, $Q D$ once daily, $S U$ sulfonylurea

\section{DISCUSSION}

As interest in understanding patient preferences grows, researchers have increased the use of stated-preference surveys, particularly DCE surveys, to aid in assessing the value of specific medical interventions. DCE surveys provide a systematic method of assessing the relative preferences of patients and other stakeholders for medication attributes and of quantifying the trade-offs they make between the benefits and risks associated with different treatment options $[18,19]$.

In this study, the results of the DCE model revealed that estimated preference weights were generally consistent with the expected ordering of attribute levels. However, there were differences in preferences between the two populations. German patients demonstrated the greatest preferences for a lower risk of GI problems, less weight gain, and oral versus injection mode of administration. Spanish patients demonstrated the greatest preferences for oral versus injection mode of administration, lower dosing frequency, and increasing probability of reaching HbA1c target. Subgroup analysis revealed significant differences in preferences among German respondents based on time since diabetes diagnosis. Both German and Spanish respondents showed subgroup preference differences based on current use of injectable treatments versus oral delivery, although how the preferences varied between subgroups was different in the German and Spanish respondents.

In the MAB analyses for both the German and Spanish respondents, respondents would require the largest increases in the probability of reaching the HbA1c target for increases in the rate of hypoglycemic events, the risk of GI problems, body weight, and dosing frequency. Interestingly, these patient relevant attributes 
were ranked higher than the clinically important attribute of risk of serious heart attack or stroke.

The findings from our study are consistent with those of similar studies. For example, Purnell et al. [18] conducted a review of studies that assessed patient preferences for non-insulin diabetes medications using a variety of quantitative methods, including DCE. When examining studies that included multiple attributes, the review found that weight loss or control, control of blood sugar, and avoidance of GI problems were identified as important. In a DCE survey of patients with T2DM in Canada, Hauber et al. [20] found that insulin-experienced respondents placed the most importance on glucose control, whereas insulin-naive respondents placed just as much significance on reducing the number of injections per day as on controlling glucose. Mohamed et al. [21] conducted a DCE survey of patients with T2DM in Sweden and Germany and reported that respondents placed the most importance on avoiding weight gain followed by glucose control. In a DCE survey of patients with T2DM in the USA comparing oral treatments, glucose control again was highly valued. The study also found that a more convenient dosing schedule (fewer pills and less frequent dosing) was more highly valued by patients who had a lower dosing burden at the time of the survey [22]. A recent DCE-based investigation in the USA and the UK focusing on physician preferences revealed the most important attributes to physicians were glucose control, risk of a fatal myocardial infarction, and weight change [19].

The current analysis also predicted preferences for treatment profiles that were similar to actual T2DM medicines. The predicted preferences support the results of the DCE analysis in that the preference for the glipizide-like and albiglutide-like medications by German respondents agrees with their preference for a non-injectable mode of administration or fewer GI problems. The preference by Spanish respondents for albiglutide-like and liraglutide-like medications agrees with their preference for less frequent dosing or no body weight gain.

The limitations of this study include reliance on the self-reported diagnosis of T2DM and
T2DM treatment and the use of a sample of patients with T2DM drawn from the consumer panel, which might not be representative of the actual German or Spanish populations of such patients. Additionally, the data collected in DCEs were based on choices among hypothetical treatment alternatives, with a focus only on clinically relevant treatment attributes. These choices were intended to simulate clinical decisions; however, they did not have the same clinical or emotional consequences of actual decisions, and differences may arise between patients' stated and actual choices.

\section{CONCLUSIONS}

Our findings suggest that both German and Spanish patients treated for T2DM were generally willing to trade efficacy for improvements in side effects, mode of administration, and dosing frequency-although differences in relative preferences were observed between the German and Spanish patient populations. Differences in preference profiles were also seen among subgroups of patients based on their current mode of administration and longer versus shorter time since diagnosis. Considering the variety of T2DM medications available, the results from this assessment suggest that engaging with patients about their specific preferences may help improve their satisfaction with T2DM treatments, which may ultimately result in improved outcomes.

\section{ACKNOWLEDGEMENTS}

This study and article processing charges were funded by GlaxoSmithKline. Medical editorial support and graphic services for early drafts were provided by Nate Connors, PhD, of NucleusX and Thea Gray of Nucleus Central. For subsequent drafts, medical writing and editorial support was provided by Elizabeth Rosenberg, PhD, of AOI Communications, L.P., and was funded by GlaxoSmithKline. All named authors meet the International Committee of Medical Journal Editors (ICMJE) criteria for authorship for this manuscript, take 
responsibility for the integrity of the work as a whole, and have given final approval to the version to be published. All authors had full access to all of the data in this study and take complete responsibility for the integrity of the data and accuracy of the data analysis.

Disclosures. Mirko Sikirica is an employee and shareholder of GlaxoSmithKline (GSK). Alan Martin is an employee and shareholder of GlaxoSmithKline (GSK). Raul Morano is an employee and shareholder of GlaxoSmithKline (GSK). Victoria Unmuessig is an employee and shareholder of GlaxoSmithKline (GSK). Carol Mansfield is an employee of RTI Health Solutions, which was contracted by GSK to conduct the study. Christine Poulos is an employee of RTI Health Solutions, which was contracted by GSK to conduct the study. Amy Pugh was an employee of RTI Health Solutions at the time of the study.

Compliance with Ethics Guidelines. The study was approved by an institutional review board of RTI International (Research Triangle Park, NC, USA). All procedures followed were in accordance with the ethical standards of the responsible committee on human experimentation (institutional and national) and with the Helsinki Declaration of 1964, as revised in 2013. All patients provided informed consent prior to their inclusion in the study.

Data Availability. The datasets during and/ or analyzed during the current study are available from the corresponding author on reasonable request.

Open Access. This article is distributed under the terms of the Creative Commons Attribution-NonCommercial 4.0 International License (http://creativecommons.org/licenses/ by-nc/4.0/), which permits any noncommercial use, distribution, and reproduction in any medium, provided you give appropriate credit to the original author(s) and the source, provide a link to the Creative Commons license, and indicate if changes were made.

\section{REFERENCES}

1. World Health Organization, regional office for Europe. Health topics/noncommunicable diseases/diabetes/data and statistics. http://www. euro.who.int/en/health-topics/noncommunicablediseases/diabetes/data-and-statistics. Accessed 27 Mar 2017.

2. Tamayo T, Rosenbauer J, Wild SH, Spijkerman AM, Baan C, Forouhi NG, et al. Diabetes in Europe: an update. Diabetes Res Clin Pract. 2014;103(2):206-17.

3. Brinks R, Tamayo T, Kowall B, Rathmann W. Prevalence of type 2 diabetes in Germany in 2040: estimates from an epidemiological model. Eur J Epidemiol. 2012;27(10):791-7.

4. Soriguer F, Goday A, Bosch-Comas A, et al. Prevalence of diabetes mellitus and impaired glucose regulation in Spain: the Di@bet.es Study. Diabetologia. 2012;55(1):88-93.

5. Inzucchi SE, Bergenstal RM, Buse JB, et al. Management of hyperglycemia in type 2 diabetes, 2015: a patient-centered approach: update to a position statement of the American Diabetes Association and the European Association for the Study of Diabetes. Diabetes Care. 2015;38(1):140-9.

6. Mallory JM, Leiter LA, Wilson TH, Reinhardt RR. Gastrointestinal safety across the albiglutide development program. Diabetes. 2014;63[Suppl 1]: Abstract 1002P. Poster presented at: American Diabetes Association 74th Scientific Sessions; June 13-17, 2014; San Francisco, CA.

7. American Diabetes Association standards of medical care in diabetes. Diabetes Care. 2016;39[Suppl 1]:S1-S106.

8. Garber AJ, Abrahamson MJ, Barzilay JI, et al. Consensus statement by the American Association of Clinical Endocrinologists and American College of Endocrinology on the comprehensive type 2 diabetes management algorithm-2016 Executive Summary. Endocr Pract. 2016;22(1):84-113.

9. Bode B, Shelmet J, Gooch B, et al. Patient perception and use of an insulin injector/glucose monitor combined device. Diabetes Educ. 2004;30(2):301-9.

10. Wang T, Conrad KA, van Brunt K, Rees TM. Attributes influencing insulin pen preference among caregivers and patients with diabetes who require greater than 20 units of mealtime insulin. J Diabetes Sci Technol. 2016;10(4):923-31.

11. Clark MD, Determann D, Petrou S, Moro D, de Bekker-Grob EW. Discrete choice experiments in 
health economics: a review of the literature. Pharmacoeconomics. 2014;32(9):883-902.

12. Hensher DA, Rose JM, Greene WH. Applied choice analysis. Cambridge: Cambridge University Press; 2005

13. Bridges JF, Hauber AB, Marshall D, et al. Conjoint analysis applications in health-a checklist: a report of the ISPOR Good Research Practices for Conjoint Analysis Task Force. Value Health. 2011;14(4):403-13.

14. Fagerlin A, Zikmund-Fisher BJ, Ubel PA. Helping patients decide: ten steps to better risk communication. J Natl Cancer Inst. 2011;103(19):1436-43.

15. Reed Johnson F, Lancsar E, Marshall D, et al. Constructing experimental designs for discrete-choice experiments: report of the ISPOR Conjoint Analysis Experimental Design Good Research Practices Task Force. Value Health. 2013;16(1):3-13.

16. Train K, Sonnier G. Mixed logit with bounded distributions of correlated partworths. In: Scarpa R, Alberini A, editors. Applications of simulation methods in environmental and resource economics. Dordrecht: Springer; 2005.
17. Train K. Discrete choice methods with simulation. Cambridge: Cambridge University Press; 2003.

18. Purnell TS, Joy S, Little E, Bridges JF, Maruthur N. Patient preferences for noninsulin diabetes medications: a systematic review. Diabetes Care. 2014;37(7):2055-62.

19. Poulos C, Gonzalez JM, Lee LJ, et al. Physician preferences for extra-glycemic effects of type 2 diabetes treatments. Diabetes Ther. 2013;4(2):443-59.

20. Hauber AB, Johnson FR, Sauriol L, Lescrauwaet B. Risking health to avoid injections: preferences of Canadians with type 2 diabetes. Diabetes Care. 2005;28(9):2243-5.

21. Mohamed AF, Zhang J, Johnson FR, et al. Avoidance of weight gain is important for oral type 2 diabetes treatments in Sweden and Germany: patient preferences. Diabetes Metab. 2013;39(5):397-403.

22. Hauber AB, Han S, Yang JC, et al. Effect of pill burden on dosing preferences, willingness to pay, and likely adherence among patients with type 2 diabetes. Patient Prefer Adherence. 2013;7:937-49. 